\title{
Cuidados paliativos
}

\section{Sedação Paliativa, Bioética e Terminalidade da Vida: Implicações na Prática Médica}

Palliative Sedation, Bioethics and Life Terminality: Implications in Medical Practice

Butores $\begin{aligned} & \text { Ana Soeiro } \\ & \text { Universidade do Estado do Pará } \\ & \text { E-mail: acsoeiro1@gmail.com } \\ & \text { (D) https://orcid.org/0000-0002-1669-3839 } \\ & \text { Victor de Souza Vasconcelos } \\ & \text { Universidade do Estado do Pará } \\ & \text { E-mail: victorvasconcelos13@gmail.com } \\ & \text { (D) https://orcid.org/0000-0002-4889-7684 }\end{aligned}$

\author{
Thalita da Rocha Bastos \\ Universidade do Estado do Pará \\ E-mail: thalitarocha08@hotmail.com \\ (DD) https://orcid.org/0000-0003-4530-609X
}

iD https://orcid.org/0000-0002-4889-7684 
Resumo

Abstract

Key words

Cuidados paliativos; medicina; bioética.

Palliative care; medicine; bioethics.

Humanization has been gaining prominence in the field of medical ethics, highlighting the importance of palliative care and palliative sedation when death proves to be an imponderable reality. This article invites bioethical reflection on palliative sedation, considering contemporary discussions on dying with dignity. This is an exploratory and descriptive study, with the participation of doctors from an oncology hospital. The findings demonstrate that palliative sedation helps in the management of pain and suffering, however, it is necessary to intensify discussions on the topic, including greater patient participation in medical decisions.

A humanização vem ganhando ampla repercussão no campo da ética médica, apontando a importância dos Cuidados Paliativos e da sedação paliativa quando a morte se revela uma imponderável realidade. 0 artigo visa estimular a reflexão bioética sobre a sedação paliativa, considerando as discussões contemporâneas sobre o morrer com dignidade. Trata-se de um estudo exploratório e descritivo, com participação de médicos/as de um hospital oncológico. Os achados demonstram que a sedação paliativa auxilia o manejo da dor e do sofrimento, entretanto, é necessária a intensificação das discussões sobre o tema, incluindo maior participação de pacientes nas decisões médicas.

Pallativecare, medicine, bioethics.

Recibido: 06/01/2021. Aceptado: 03/02/2022 


\section{Introdução}

Os Cuidados Paliativos são indicados para pacientes cuja doença encontra-se fora de possibilidades de cura, com prognóstico de óbito inevitável e previsível (Costa \& Duarte, 2019). Nesse contexto, a Medicina paliativista tem por finalidade o controle dos sintomas associados à doença, o alívio da dor e a melhoria da qualidade de vida do/a paciente até o momento de sua morte, sendo a terapia de sedação paliativa (SP) uma das principais ferramentas para atingir esses objetivos, em especial quando as condutas paliativistas usuais se mostram ineficazes (Schur et al., 2016; Bodnar, 2017; Freitas et al., 2020).

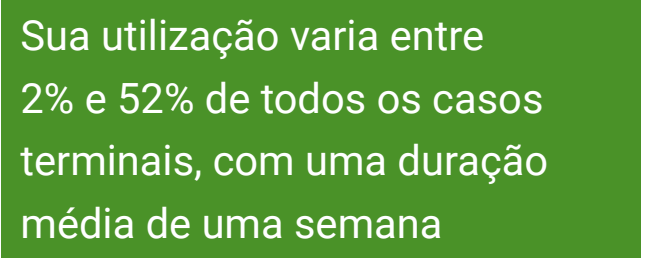

A Associação Europeia para Cuidados Paliativos (EAPC) define SP como o uso monitorado de medicamentos com a intensão de induzir um estado de diminuição ou interrupção da consciência, no intuito de aliviar o sofrimento causado por sintomas que não podem ser tratados de outra maneira (Schur et al., 2016). A conduta terapêutica consiste no uso de fármacos sedativos para proporcionar alívio do sofrimento desencadeado por sintomas refratários, inerentes à condição clínica do paciente, por meio da redução do nível de consciência (Schur et al., 2016; Menezes \& Lima, 2018; Menezes \& Figueiredo, 2019).

Vale ressaltar que o foco da terapia não é apressar a morte, sendo a necessidade de controle dos sintomas o fator determinante da escolha da medicação, dose e duração da terapia, bem como do grau de redução de consciência (Menezes \& Lima, 2018). Ao se optar pela implementação da SP, a meta ideal é preservar a capacidade do/a paciente de interagir com seus familiares/cuidadores, ao passo que se busca o adequado controle dos sintomas refratários, utilizando a menor dose possível do medicamento (Bobb, 2016).

A SP é uma das únicas condutas utilizadas no final da vida universalmente aceitas. Sua utilização, segundo a literatura (Carreño, Vásquez \& Insignares, 2021), varia entre $2 \%$ e $52 \%$ de todos os casos terminais, com uma duração média de uma semana, sendo mais frequente nas últimas 48 horas de vida do paciente. Essas diferenças podem ser reflexo do ambiente de trabalho, de protocolos institucionais, e também, das experiências e percepções de profissionais envolvidos/as no processo, uma variável que vem ganhando crescente ênfase nas reflexões sobre ética médica e Bioética (Spinelli, Kurashima \& De Gutiérrez, 2015). Isto ocorre porque a SP é uma escolha permeada por concepções e valores morais do/a médico/a, que repercutem diretamente em suas condutas, reafirmando assim a dimensão humana inerente à profissão.

Dentre os principais sintomas que determinam a indicação de SP, merecem destaque o delirium, a dor intensa, dispneia, fadiga e a presença de náuseas e vômito (Azoulay et al., 2016; Fernández \& Suárez, 2018). A SP pode ser classificada conforme o nível de rebaixamento da consciência em leve, quando o/a paciente permanece desperto/a, e profunda, quando o/a paciente se encontra em um estado de total inconsciência. De acordo com sua duração, pode ser dividida em intermitente, quando é feita durante um 
período do dia, e contínua, quando o/a paciente permanece sedado/a até o momento do óbito (Leboul et al., 2017).

Mesmo sendo um procedimento de natureza técnica, a indicação da SP pode ser uma decisão difícil de manejar, particularmente por sua relação com o tema da morte, discussão que nas últimas décadas tem ganhado maior visibilidade no espaço da Medicina, com a consolidação dos Cuidados Paliativos (Siqueira-Batista \& Schramm, 2005; Alonso, 2013; Menezes \& Lima, 2018).

Tal realidade faz com que muitos/as médicos/as enfrentem dúvidas acerca do momento certo de início da sedação, sobre a responsabilidade na decisão de iniciar o procedimento e as questões éticas envolvidas. Tais variáveis podem interferir na conduta clínica, em especial quando se consideram os fatores culturais que fundamentam a relação médico/paciente/família na realidade latino-americana,

Mesmo sendo um procedimento de natureza técnica, a

indicação da SP pode ser uma decisão difícil de manejar,

particularmente por sua relação com o tema da morte onde o silenciamento das informações junto ao/a paciente costuma ser uma realidade frequente (Menezes \& Lima, 2018).

Ainda que a indicação de início da SP seja definida pela equipe médica, com base nos critérios já estabelecidos na literatura, a decisão de iniciar a SP deveria, preferencialmente, incluir o paciente, uma vez que ele é quem melhor pode definir quando o sofrimento desencadeado pelos sintomas se torna intolerável (Spinelli, Kurashima \& De Gutiérrez, 2015). Assim, caberia ao/à profissional explicar de maneira clara e empática a pacientes e familiares/cuidadores a evolução dos sintomas refratários e a razão de não ser mais possível controlá-los por condutas convencionais, os riscos e benefícios da SP e os objetivos da terapia. Mediante tais informações, o/a paciente ou seu/sua responsável podem exercer sua autonomia no consentimento livre e esclarecido, o qual deverá ser devidamente registrado no prontuário (Bobb, 2016; Coelho \& Yankaskas, 2017; Alves et al., 2019).

Especialmente na sedação profunda, o início da SP é uma etapa que tende a intensificar o sentimento de luto vivido por pacientes e/ou por sua família, pois representa uma linha demarcatória de um processo que pode ser vivido com alívio, mas também com culpa e angústia, em especial por parte da equipe e dos/as cuidadores/as. Nesse sentido, é importante que o/a médico/a possa encorajar familiares a permanecerem ao lado do/a paciente e lhes oferecer todas as informações e apoio psicológico necessário em preparação à possibilidade de óbito (Andrade, Costa \& Lopes, 2013; Fernández \& Suárez, 2018). Entretanto, estudos têm apontado para as dificuldades pessoais de médicos/as em situações ligadas à morte, o que possivelmente é reforçado por lacunas presentes desde a formação acadêmica, e que acabam também causando desconforto e sofrimento ao/à profissional para abordar tais assuntos (Leboul et al., 2017; Blasco, 2018; Ribeiro \& Poles, 2019).

No cenário atual de consolidação da Bioética, crescente interesse tem sido dedicado à temática do "morrer com dignidade", reforçando assim a necessidade de repensar a forma como a Ciência e a tecnologia têm sido usadas nos cuidados em saúde, em especial nas decisões médicas sobre a morte e o morrer (Siqueira-Batista \& Schramm, 2005; Pessini, 2011; Oliveira et al., 2016). 
A temática da SP ainda demanda intensas reflexões, especialmente quando se avaliam os dilemas éticos e bioéticos envolvidos, incluindo as inúmeras críticas relacionadas à medicalização da morte e ao prolongamento da dor e do sofrimento (Pessini, 2002). Escolher esse tema como objeto de investigação é também reconhecer as inquietações que o assunto desperta, abrindo espaço para novas reflexões, capazes de responder aos atuais dilemas éticos da prática médica na busca pela dignidade do viver e do morrer.

Ao considerar a SP como temática do presente estudo, utilizou-se como dispositivo de análise a experiência de médicos/as de um hospital público em relação ao tema, na tentativa de compreender as condições em que o procedimento é realizado, incluindo nesse olhar o entrelaçamento da dimensão técnica, humana e ética da prática médica.

\section{Método}

Trata-se de uma pesquisa exploratória, descritiva, com uso de metodologia predominantemente qualitativa, e que teve como instituição coparticipante um hospital público estadual localizado na região metropolitana de Belém, Pará, Brasil. O hospital é referência para tratamento oncológico e recebe pacientes oriundos de diferentes municípios.

Trata-se de uma pesquisa

exploratória, descritiva,

com uso de metodologia

predominantemente qualitativa
A pesquisa foi desenvolvida conforme os preceitos estabelecidos pela Declaração de Helsinque e pelo Código de Nuremberg, respeitadas as normas de Regulamentação de Pesquisa Envolvendo Seres Humanos, Resolução n. 466/12 do Conselho Nacional de Saúde (Brasil, 2012), após a aprovação pelo Comitê de Ética em Pesquisa do Hospital Ophir Loyola, sob o Parecer n. 2.423.247.

Os/as participantes da pesquisa foram médicos/as com atuação no Centro de Terapia Intensiva (CTI), Clínica de Cuidados Paliativos Oncológicos (CCPO) e Oncologia Clínica. Esses setores do hospital foram priorizados por serem áreas nas quais a SP é uma conduta muito frequente.

No total, participaram da pesquisa 11 médicos, sendo dois (18,18\%) do sexo masculino e nove $(81,81 \%)$ do sexo feminino. Deste total, sete $(63,63 \%)$ médicos/a atuavam no CTI e três $(27,27 \%)$ na CCPO. Além destes, foi incluída também uma médica oncologista clínica, vinculada à CCPO.

A segunda fase incluiu a aplicação presencial de um questionário semiestruturado aos/às participantes, contendo perguntas abertas e fechadas. 0 questionário foi aplicado pessoalmente pela equipe de pesquisadores que na ocasião solicitou permissão para gravação das respostas, de modo a garantir a fidedignidade nos registros. O local de aplicação do questionário foi o hospital, priorizando-se um ambiente que garantisse a privacidade e sigilo das informações. Todo o procedimento foi fundamentado na aceitação livre e voluntária dos/as participantes, formalizada mediante assinatura do Termo de Consentimento Livre e Esclarecido (TCLE). 
Os dados foram analisados conforme o método da Análise de Conteúdo de Bardin (Minayo, 2004), estratégia de análise já consagrada no campo das Ciências Humanas e Sociais em Saúde, e bastante utilizada como ferramenta de análise em estudos de natureza qualitativa. Embora as pesquisas na área médica ainda mantenham uma forte influência de abordagens quantitativas, tem sido crescente também o uso desse tipo de referencial, especialmente quando estão em análise percepções e opiniões pessoais de participantes da pesquisa sobre o tema em questão. 0 uso dessa técnica contribui para tornar replicáveis e válidas as inferências sobre dados de um determinado contexto, por meio de procedimentos especializados e científicos (Minayo, 2004).

\section{Resultados e discussão}

\subsection{A sedação paliativa como uma ferramenta de conforto diante da finitude da vida}

Como um dos achados do presente estudo, observou-se uma homogeneidade nas respostas em relação à compreensão dos/as participantes sobre o uso da SP na prática médica, já que, sem exceção, concordaram que se trata de uma intervenção utilizada com pacientes fora da possibilidade de recuperação, como forma de tornar o processo de morrer mais digno e humanizado (Alonso, 2013). Do total de

Durante a coleta de dados, observou-se receio de alguns/ algumas profissionais em abordar as implicações éticas da SP entrevistados/as, oito $(72,72 \%)$ destacaram que o principal foco da SP é fornecer conforto nos últimos momentos, permitindo um final de vida com controle adequado dos sintomas.

Durante a coleta de dados, observou-se receio de alguns/algumas profissionais em abordar as implicações éticas da SP, particularmente no que concerne ao momento propício para sua indicação e na repercussão do seu início para paciente e família, revelando cuidado em não transmitir a impressão de que o procedimento seria utilizado para antecipar a morte. Essa preocupação foi mais frequente por parte de profissionais que não tiveram treinamento prévio em Cuidados Paliativos, o que demonstra um diferencial importante no manejo da técnica (Eich, Verdi \& Martins, 2015).

Embora saibam descrever tecnicamente a SP, médicos/as atuantes no CTI relataram pouco contato com o tema ao longo de sua Graduação, sendo que cinco $(45,45 \%)$ procuraram um aperfeiçoamento externo por meio de cursos de atualização, motivados pelos desafios impostos pelo contato cotidiano com pacientes graves. No que concerne a profissionais do CCPO/oncologia clínica, todos/as tiveram módulos de discussão do tema durante a Residência, assim como participam de atividades complementares como cursos de atualização e jornadas científicas, o que justifica nas suas falas uma maior segurança quanto à prática da SP. $O$ principal receio observado, no que concerne aos aspectos éticos, foi que a sedação possa ser interpretada como uma forma de eutanásia. 
De modo geral, observou-se que os/as participantes delimitam de forma precisa a diferença entre a sedação e a antecipação da morte pela ação médica, já que este seria um ato condenável sob o ponto de vista da legislação brasileira e da ética médica e, portanto, moralmente inaceitável (Spineli, Kurashima \& De Gutiérrez, 2015; Castro et al., 2016). Um dos argumentos utilizados se refere à intencionalidade da ação, já que a principal diferença entre a SP e a eutanásia residiria na intenção, haja vista que ainda que se vislumbre a possibilidade de evolução a óbito, este não seria o principal motivo para escolha deste procedimento, mesmo quando se considera

O principal receio observado,

no que concerne aos aspectos

éticos, foi que a sedação possa

ser interpretada como uma

forma de eutanásia o duplo efeito (Menezes \& Lima, 2018; Menezes \& Figueiredo, 2019).

Na SP, a intenção é o controle dos sintomas refratários por meio da redução do nível de consciência, enquanto a finalidade da eutanásia é a antecipação do término da vida (Oliveira, 2019). Entretanto, foi destacado que muitos medicamentos usados no controle dos sintomas refratários podem ter efeitos adversos capazes de acelerar a morte de pacientes, o que justifica a cautela de alguns/algumas profissionais em relação ao seu uso. Nesse aspecto, é perfeitamente compreensível que os/as participantes se sintam apreensivos/as em fazer uma distinção precisa entre estes dois procedimentos, de modo a não transmitir a impressão que estariam ultrapassando um limite supostamente intransponível, que seria o de decidir sobre como e quando alguém deve morrer.

\subsection{Indicações de Sedação Paliativa: 0 enlace para o alívio da dor e do sofrimento existencial}

Dentre as principais indicações para início da SP, foi consenso entre entrevistados/as que é uma estratégia indicada para controle da dor refratária à analgesia usual. Pouco mais da metade dos/as participantes também destacou o desconforto respiratório/ dispneia como motivo principal de sedação de pacientes (Azoulay et al., 2016; Díaz et al., 2019).

Entretanto, do total de participantes, oito $(72,72 \%)$ responderam que essa modalidade de paliação pode ser usada para alívio da dor e do sofrimento físico, assim como do sofrimento psicológico. Outros/as três $(27,27 \%)$ também incluíram como indicação o alívio do sofrimento vivenciado por familiares diante do quadro do/a paciente. Tais relatos denotam a importância de uma abordagem onde paciente e família como um todo sejam considerados o foco dos cuidados médicos, até porque muitas vezes são os/as familiares que concordam, em conjunto com o/a médico/a, pela realização da SP.

No que concerne à indicação de SP para minimização do sofrimento puramente psicológico dos/as pacientes, seis $(54,54 \%)$ médicos foram favoráveis à realização do procedimento, apontando como principais justificativas o alívio da aflição experimentada diante da proximidade da morte e suas repercussões na saúde mental do/a paciente, a exemplo dos quadros depressivos e distúrbios do sono, fatores que estão intimamente relacionados a uma deterioração da qualidade de vida. Uma médica afırmou que a opção de sedação deve ser individualizada para cada caso, mas destacou que toda 
forma de confortar o/a paciente é válida. Entretanto, do total de entrevistados/as, quatro $(36,36 \%)$ profissionais se posicionaram contra a sedação, alegando principalmente que a decisão de iniciar a SP deve se basear apenas na evolução clínica, e que existem outras formas de ajudar pacientes a lidar com esse sofrimento emocional.

De modo geral, observou-se que tanto o desconforto físico como psicológico são aspectos que servem de parâmetro para a indicação dessa terapêutica. Entretanto, o apoio dos/as psicólogos/as da equipe foi ressaltado como fundamental na abordagem clínica, haja vista que intervenções dessa natureza podem também contribuir para meIhorar as condições psicológicas do/a paciente, evitando assim que a SP seja utilizada como única opção terapêutica.

Foi perguntado a médicos/as

se consideravam importante

a existência de um Comitê de

Ética médica ou de Bioética

para auxiliar na indicação da SP

Segundo os/as entrevistados/as não há no hospital nenhum protocolo formal para auxiliar-profissionais na indicação da SP, sendo esta pautada primariamente na evolução clínica do/a paciente, na experiência de cada médico/a e nas discussões entre a equipe. Do total de médicos/as, sete $(63,63 \%)$ afirmaram que seria útil a implementação de um protocolo institucional, principalmente para auxiliar profissionais mais inexperientes que ainda não tem contato com a SP, bem como para otimizar a prescrição dos fármacos utilizados. Quase todos os/as participantes destacaram a importância da equipe multiprofissional na decisão de iniciar a sedação, sendo enfatizada a importância da troca de experiências com colegas no processo de tomada de decisão.

Foi perguntado a médicos/as se consideravam importante a existência de um Comitê de Ética médica ou de Bioética para auxiliar na indicação da SP. Nesse aspecto, as respostas foram controversas, sendo que cinco $(45,45 \%)$ entrevistados/as consideraram que não seria necessário, pois a discussão dos aspectos éticos deve ser feita antes do momento da indicação, para dar embasamento ao/a profissional para lidar com esses casos conforme eles surjam. Demais médicos/as consideram que a existência do Comitê seria útil para respaldar o/a médico/a diante da necessidade de realização do procedimento, bem como para criação de instrumentos que facilitem o entendimento do processo por todas as partes envolvidas. Nesse sentido, duas médicas destacaram a validade da criação de um termo de consentimento para a realização da SP, de forma a assegurar o entendimento do/a paciente e de familiares e amenizar a insegurança profissional quanto à indicação do procedimento.

Bobb (2016) destaca a importância de uma política institucional na utilização da SP, incluindo a orientação de um Comitê de Ética antes da recomendação desse tipo de terapia. Entretanto, na realidade brasileira, Comitês de Bioética clínica ou hospitalar, os quais teriam um importante papel nesse cenário, ainda são muito escassos, tornando difícil o compartilhamento das decisões e a deliberação conjunta das questões morais envolvidas (Eich, Verdi \& Martins, 2015). Assim, em muitos casos, a escolha pelo procedimento acaba se reduzindo a uma questão técnica e uma decisão final do médico, quase sempre com pouca ou nenhuma participação do/a paciente (Motta et al., 2016).

As dificuldades descritas na literatura em relação à conduta terapêutica apontam para dois grandes dilemas éticos que concernem à temática de SP: o uso de fármacos para 
o controle do sofrimento psicológico/existencial relacionado ao processo de morrer e o medo de que a SP antecipe a morte (Spineli, Kurashima \& De Gutiérrez, 2015). A decisão de iniciar SP em razão do sofrimento psicológico/existencial deve ser tomada com extrema cautela e somente após análise por uma equipe multiprofissional, e quando implementada a sedação, é recomendável que seja feita de modo intermitente (Bobb, 2016).

Os dados obtidos no presente estudo demonstram a importância de reconhecer as várias dimensões da dor e do sofrimento existencial experimentado por pacientes, revelando assim a multiplicidade de variáveis a serem consideradas por médicos/as como critérios de indicação da SP. Certamente, se trata de um tema no qual as habilidades e conhecimentos técnicos devem se somar às atitudes de empatia e compaixão, que constituem importantes elementos da humanização do cuidado (Alonso, 2013; Blasco, 2018).

\subsection{Aspectos técnicos da Sedação Paliativa}

No que concerne ao local de realização da SP (hospital ou residência do paciente), a maior parte dos/as entrevistados/as acredita que a decisão deve ser individualizada para cada caso. Entretanto, 7 (63,63\%) médicos/as destacaram que em decorrência das medicações utilizadas serem normalmente administradas por via endovenosa, pela possibilidade de monitorização contínua, e para evitar possíveis descompensações do quadro clínico, é recomendável que o/a paciente permaneça preferencialmente no hospital. Ainda assim, foi ressaltado que pode haver a possibilidade de o/a paciente ser acompanhado/a em casa, desde que haja um controle adequa-

A maioria dos/as participantes consideraram que o ambiente familiar é o melhor lugar para o/a paciente viver suas últimas horas do dos sintomas, incluindo o uso de medicações por via oral. A maioria dos/as participantes consideraram que o ambiente familiar é o melhor lugar para o/a paciente viver suas últimas horas.

As principais medicações utilizadas no hospital para o controle dos sintomas são morfina e fentanil, usadas para controle da dor, e midazolam, para induzir a sedação. Segundo a literatura, o midazolam é o fármaco de escolha para o início e manutenção da sedação. Este medicamento, pertencente à classe dos benzodiazepínicos, costuma ser efetivo no controle da maior parte dos sintomas refratários, possuindo efeito ansiolítico, sedativo, anticonvulsivante e antiespasmódico. A administração pode ser feita por via intravenosa ou subcutânea. A dose é dependente do quadro do paciente e varia de 150 a 200 mg/dia (Azoulay et al., 2016; Bobb, 2016; Fernández \& Suárez, 2018).

De maneira geral, os/as participantes afirmaram que administram inicialmente os opióides para aliviar a dor, sendo acrescentado o benzodiazepínico nos casos refratários. Quanto à manutenção das medicações, as respostas variaram, havendo casos em que pacientes são mantidos/as em sedação até o momento do óbito e, outros em que a dose das medicações é diminuída para o menor volume capaz de controlar os sintomas. 


\subsection{Sedação Paliativa e Ortotanásia: A boa morte como princípio do cuidado}

Segundo os/as entrevistados/as, a decisão de quais procedimentos devem ser realizados e qual o momento de se instituir Cuidados Paliativos é uma decisão difícil e que deve ser discutida e pactuada entre o/a profissional, o/a paciente, familiares e a equipe, pois, em última análise, irá determinar todo o processo de morrer de um ser humano. Entretanto, quando comparadas as respostas dos/as médicos/as, e considerando o cenário de atuação, foi verificado que na clínica de Cuidados Paliativos, é mais comum que as decisões sejam tomadas de forma coletiva e com maior participação do/a paciente e família. A explicação para essa diferença possivelmente reside no preparo técnico diferenciado dos/as profissionais que lá atuam para lidar com pessoas que enfrentam doenças em fase terminal.

Muitas vezes, o/a médico/a

precisa desconstruir receios

e preconceitos de pacientes e

familiares em relação à SP

Um fato a ser considerado é que na UTI muitos/as pacientes não estão em condições para decidir sobre os procedimentos médicos, por estarem muito debilitados/as ou inconscientes. No que concerne ao diálogo com o/a paciente, observou-se que ele não é frequente na UTI, haja vista que pacientes muitas vezes estão entubados/as ou com complicações graves que impedem a comunicação. Nesses casos a avaliação do conforto se baseia em sinais clínicos característicos de dor ou desconforto respiratório como fácies de dor, aumento da pressão arterial, da frequência cardíaca ou presença de taquipneia/dispneia. Havendo a indicação de SP, a família é contatada para autorizar o procedimento, nesse momento o caso é explicado e a SP é iniciada.

Pacientes do CCPO, por sua vez, apresentam um quadro mais estável, tornando mais viável o diálogo com o médico. Nesses casos, o/a paciente é mais participativo do processo de tomada de decisão, sendo relatado que a maior prioridade da intervenção médica é não deixar o paciente sentir dor. A aceitação familiar também parece ser maior nesse setor, possivelmente pelo maior contato com os profissionais e com a equipe multidisciplinar. Foi relatado que há uma grande rede de amparo à família no hospital, com destaque para o "consultório do luto" no qual a família ainda retorna ao hospital mesmo após o óbito, a fim de receber suporte emocional e psicológico.

Muitas vezes, o/a médico/a precisa desconstruir receios e preconceitos de pacientes e familiares em relação à SP. Como exemplo, foi mencionado que pacientes que nunca fizeram uso das medicações utilizadas em SP apresentam maior recusa ao procedimento, a exemplo da prescrição de morfina, que por vezes pode ser mal interpretada por pacientes virgens de tratamento, por associarem seu uso à impossibilidade de cura.

A comunicação com o/a paciente e seus familiares foi destacada como um elemento fundamental do vínculo terapêutico, principalmente na CCPO. Na opinião dos/as participantes, uma boa comunicação ajuda a romper preconceitos, acrescentando à terapêutica, uma função educativa. Foi enfatizado que a compreensão das informações e um adequado suporte médico e psicológico, faz com que alguns pacientes solicitem a implementação da SP e como resultado, familiares também se sentem menos pressionados em relação a essa decisão. 
Foi consenso entre os/as participantes a necessidade do diálogo com a família acerca da SP. Os dados revelam que, de maneira geral, quando bem orientada, a família não se opõe a tal prática, pois seu principal desejo é que seu ente querido não sinta dor e tenha um final de vida sem sofrimento. Os/as participantes afirmaram que conseguir o pleno entendimento dos familiares é o maior desafio nesse processo, sendo necessária uma abordagem multidisciplinar para garantir o melhor desfecho possível. Na Clínica de Cuidados Paliativos, diante de quadros mais graves em que há a recusa familiar em iniciar o procedimento, é feita uma reunião da equipe com a família para explicar o quadro, esclarecer dúvidas e acolher as aflições de familiares.

Merece destaque a importância atribuída ao/a profissional oncologista clínico no processo de tomada de decisão acerca da adoção da SP como opção terapêutica. No CTI, a decisão de iniciar a SP fica a cargo do/a médico/a diarista, entretanto quando possível, é solicitada a avaliação da oncologia clínica. A CCPO, por sua vez, possui duas oncologistas que trabalham em parceria com o setor, constando dentre suas atribuições, o suporte à indicação da SP.

Houve um grande destaque por todos os/as médicos/as da im-

Na opinião dos/as participantes, uma boa comunicação ajuda

a romper preconceitos,

acrescentando à terapêutica,

uma função educativa portância da discussão do tema durante as reuniões da equipe, sendo este um espaço para troca de experiências e ajuste das condutas e abordagens à família e a pacientes.

Por fim, observou-se que o envolvimento da família no processo de comunicação e tomada de decisões costuma ser maior quando comparada à participação do/a paciente, o que resulta em questões éticas que precisam ser debatidas, em especial quando se considera a importância da autonomia do paciente sob cuidados em fim de vida. Entretanto, de forma geral, apesar dos avanços alcançados com a consolidação dos Cuidados Paliativos, observou-se que a opção pela SP ainda permanece sendo majoritariamente uma decisão técnica da equipe médica, com pouca participação do/as paciente.

Particularmente nos Cuidados Paliativos, a comunicação do/a médico/a com o/a paciente tem grande importância no processo de tomada de decisão, como já mencionado. É frequente que estes tenham dificuldade de abordar temas relacionados à finitude, o que muitas vezes os/as impede de compartilhar com o/a paciente a responsabilidade diante das escolhas terapêuticas possíveis (Andrade, Costa \& Lopes, 2013). Entretanto, tal realidade tem sofrido grandes modificações diante do enfraquecimento do paternalismo médico face à crescente valorização da autonomia de pacientes. Embora não tenham sido aprovadas na legislação brasileira, as Diretivas Antecipadas de Vontade (DAV) têm sido utilizadas como parâmetros reguladores do exercício profissional e representam um grande avanço no que diz respeito aos direitos do/a paciente e à valorização de sua autonomia (Pessini, 2011; Conselho Federal de Medicina, 2012).

Atualmente, sabe-se que há países que reconhecem juridicamente o direito de o/a paciente optar previamente pelos procedimentos médicos que deseja que sejam realizados em caso de uma doença grave e com prognóstico reservado, o que poderia incluir a opção pela realização da SP. Entretanto, muitos países ainda enfrentam muitas dificul- 
dades para colocar em prática o direito à autonomia do/a paciente nas decisões sobre a própria morte, não só como resultado de fatores culturais e religiosos, mas também em razão questões legais que não podem ser negligenciadas (Eich, Verdi \& Martins, 2015; Motta, Oliveira \& Siqueira-Batista, 2016).

Mesmo com as grandes conquistas na área médica e farmacológica, a morte ainda continua a ser um grande desafio na prática médica. 0 que está no cerne das discussões atuais não é mais a imperiosa necessidade de evitar a morte, mas sim o dever de contribuir para que ela ocorra da melhor forma possível, com menos dor e sofrimento e com mais dignidade (Siqueira-Batista \& Schramm, 2005; Pessini, 2011; Costa \& Duarte, 2019; Costa, Caldato \& Furlaneto, 2019). Nesse aspecto, a SP pode ser uma importante estratégia para amenizar o impacto desta experiência, tanto em sua dimensão física como existencial, em direção à humanização do processo de morte e morrer (Alonso, 2013; Fernández \& Suárez, 2018; Alves et al., 2019).

\section{Conclusão}

Diante dos achados, observa-se a importância de que assuntos relacionados à terminalidade da vida sejam intensificados na formação médica. 0 uso da SP para o alívio da dor e do sofrimento de pacientes com doenças incuráveis está longe de ser uma decisão exclusivamente técnica. Nesse aspecto, ainda se faz necessária a introdução dessa temática nas discussões sobre a dignidade do morrer, o que implica no reconhecimento do lugar ocupado por pacientes como sujeitos autônomos de seu processo de cuidado.

Apesar dos avanços alcançados, é preciso romper com as barreiras que impedem o compartilhamento das decisões clínicas frente a essa inexorável realidade da existência humana que é a morte. Nesse sentido, a Bioética se constitui como um importante campo de conhecimento com diferentes ofertas teóricas e metodológicas diante da complexidade do tema.

Novos tempos convocam o poder público e a sociedade a debater sobre o tema diante das inúmeras possibilidades do viver e do morrer, os quais sem dúvida, continuarão a balizar as intervenções médicas. Os limites tênues que muitas vezes delimitam a beneficência e não maleficência como estruturantes da ética médica precisam ser revisitados diante dos novos avanços da Ciência e da tecnologia, mas, sobretudo, em íntima relação às concepções vigentes sobre as possibilidades e limites de intervenção na manutenção e prolongamento da vida.

Os achados demonstram que os Cuidados Paliativos têm tido um importante papel no sentido de fomentar importantes reflexões quanto às responsabilidades e deveres profissionais diante desse novo cenário que desponta. Diferentemente do passado, as pessoas doentes despontaram na cena de cuidado como sujeitos de direito, mas ainda é preciso que os/as médicos/as validem esse lugar, o que implicará em novos modelos de relação, menos paternalistas e autoritárias. Que a Medicina abrace cada vez mais essa proposta, transformando-a numa diretriz ética dos tempos atuais. 


\section{Referencias}

Alonso, J. P. (2013). Cuidados paliativos: entre la humanización y la medicalización del final de la vida. Ciência \& Saúde Coletiva, 18(9), 2541-2548. https://doi.org/10.1590/S1413-81232013000900008

Alves, R. S. F., Cunha, E. C. N., Santos, G. C., \& Melo, M. O. (2019). Cuidados paliativos: alternativa para o cuidado essencial no fim da vida. Psicologia: Ciência e Profissão, 39(e185734), 1-15. https://doi. org/10.1590/1982-3703003185734

Andrade, C. G., Costa, S. F. G., \& Lopes, M. E. L. (2013). Cuidados paliativos: a comunicação como estratégia de cuidado para o paciente em fase terminal. Ciência \& Saúde Coletiva, 18(9), 2523-2530. https://doi. org/10.1590/S1413-81232013000900006

Azoulay, D., Shahal-Gassner, R., Yehezkel, M., Eliyahu, E., Weigert, N., Ein-Mor, E., \& Jacobs, J. M. (2016). Palliative sedation at the end of life: patterns of use in an Israeli hospice. American Journal of Hospice and Palliative Medicine, 33(4), 369-373. https://doi.org/10.1177\%2F1049909115572991

Blasco, P. G. (2018). A ordem dos fatores altera o produto. Reflexões sobre educação médica e cuidados paliativos. Educación médica, 19(2), 104-114. https://doi.org/10.1016/j.edumed.2016.07.010

Bobb, B. (2016). A Review of Palliative Sedation. The Nursing clinics of North America, 51(3), 449-457. https:// doi.org/10.1016/j.cnur.2016.05.008

Bodnar, J. (2017). A review of agents for palliative sedation/continuous deep sedation: pharmacology and practical applications. Journal of pain \& palliative care pharmacotherapy, 31(1), 16-37. https://doi.org/1 $0.1080 / 15360288.2017 .1279502$

Brasil. Conselho Nacional de Saúde. (2012). Resolução N. ${ }^{\circ}$ 466, de 12 de dezembro de 2012. Dispõe sobre as diretrizes e normas regulamentadoras de pesquisas envolvendo os seres humanos. Diário Oficial da União, (12).

Carreño, V. Q., Vásquez, C. M., \& Insignares, C. A. (2021). Sedación Paliativa en Enfermedad Terminal. Revista Colombiana de Cancerología, 26(1), 1-11.

Castro, M. P. R. D., Antunes, G. C., Marcon, L. M. P., Andrade, L. S., Rückl, S., \& Andrade, V. L. Â. (2016). Eutanásia e suicídio assistido em países ocidentais: revisão sistemática. Revista Bioética, 24(2), 355-367. https:// doi.org/10.1590/1983-80422016242136

Coelho, C. B. T., \& Yankaskas, J. R. (2017). Novos conceitos em cuidados paliativos na unidade de terapia intensiva. Revista Brasileira de Terapia Intensiva, 29(2), 222-230.

Conselho Federal de Medicina. (2012). Resolução CFM n. 1.995, de 9 de agosto de 2012. Dispõe sobre as diretivas antecipadas de vontade dos pacientes. Diário Oficial da União, (170).

Costa, B. P., \& Duarte, L. A. (2019). Reflexões bioéticas sobre finitude da vida, cuidados paliativos e fisioterapia. Revista Bioética, 27(3). https://doi.org/10.1590/1983-80422019273335

Costa, T. N. M., Caldato, M. C. F., \& Furlaneto, I. P. (2019). Percepção de formandos de medicina sobre a terminalidade da vida. Revista Bioética, 27(4), 661-669. https://doi.org/10.1590/1983-80422019274349

Díaz, N. A., Menocal, M. F., Espinosa, D. E., Duca, I. M., Giménez, A. C., Segovia, R., ... Zarbá, J. J. (2019). Sedación Paliativa Terminal em Cáncer. Experiência Institucional. Oncologia Clínica, 24, 56-59.

Eich, M., Verdi, M. I. M., \& Martins, P. P. S. (2015). Deliberación moral en sedación paliativa destinada a un equipo de cuidados paliativos oncológicos. Revista Bioética, 23(3), 583-592. https://doi.org/10.1590/198380422015233095 
Fernández, M. L., \& Suárez L. L. (2018). Sedación paliativa en el paciente en situación terminal. RCA Grupo Editor, 3(22), 35-53.

Freitas, R. de, Oliveira, L. A. F. de, Rosa, K. S. da C., Borsatto, A. Z., Sampaio, S. G. dos S. M., Sales, B. R., Krieger, M. V., Esteves, E. M. F. L., Silva, E. D. da, \& Oliveira, L. C. de. (2020). Cuidados Paliativos em Pacientes com Câncer Avançado e Covid-19. Revista Brasileira de Cancerologia, 66(e-1077), 1-5. https://doi. org/10.32635/2176-9745.RBC.2020v66nTemaAtual.1077

Leboul, D., Aubry, R., Peter, J., Royer V., Richard J., \& Guirimand F. (2017). Palliative sedation challenging the professional competency of health care providers and staff: a qualitative focus group and personal written narrative study. BMC Palliative Care, 16(25), 2-12. https://doi.org/10.1186/s12904-017-0198-8

Menezes, M. S., \& Figueiredo, M. G. (2019). O papel da sedacão paliativa no fim da vida: aspectos médicos e éticos - Revisão. Revista Brasileira de Anestesiologia, 69(1), 72-77. https://doi.org/10.1016/j. bjan.2018.03.002

Menezes, R. A., \& Lima, C. P. (2018). Sedação paliativa em fim de vida: debates em torno das prescrições médicas. Revista M, 3(6), 405-420. https://doi.org/10.9789/2525-3050.2018.v3i6.405-420

Motta, L. C. S., Oliveira, L. N., Silva, E., \& Siqueira-Batista, R. (2016). Tomada de decisão em (bio) ética clínica: abordagens contemporâneas. Revista Bioética, 24(2), 304-314. https://doi.org/10.1590/198380422016242131

Minayo, M. C. S. (2004). 0 desafio do conhecimento. Pesquisa qualitativa em saúde.

Oliveira, D. A. T. (2019). Dignidade da pessoa humana, cuidados paliativos e ortotanásia. Revista Amagis Jurídica, (7), 33-56.

Oliveira, J. R. D., Ferreira, A. C., Rezende, N. A. D., \& Castro, L. P. D. (2016). Reflexões sobre o ensino de bioética e cuidados paliativos nas escolas médicas do Estado de Minas Gerais, Brasil. Revista Brasileira de Educação Médica, 40(3), 364-373. https://doi.org/10.1590/1981-52712015v40n3e01632015

Pessini, L. (2002). Humanização da dor e sofrimento humano no contexto hospitalar. Revista de Bioética, 10(2), 51-67.

Pessini, L. (2011). Algumas questões éticas urgentes em situações críticas e de final de vida. Em L. Bertachini \& L. Pessini (orgs.), Encanto e responsabilidade no cuidado da vida: lidando com desafios éticos em situações críticas e de final de vida (pp. 223-240). Centro Universitário São Camilo.

Ribeiro, J. R., \& Poles, K. (2019). Cuidados Paliativos: Prática dos Médicos da Estratégia Saúde da Família. Revista Brasileira de Educação Médica, 43(3), 62-72. https://doi.org/10.1590/1981-52712015v43n3rb20180172

Schur, S., Weixler, D., Gabl, C., Kreye, G., Likar, R., Masel, E. K., ... \& Watzke, H. H. (2016). Sedation at the end of life-a nation-wide study in palliative care units in Austria. BMC Palliative Care, 15(50), 1-8. https://doi. org/10.1186/s12904-016-0121-8

Siqueira-Batista, R., \& Schramm, F. R. (2005). Conversações sobre a "boa morte": o debate bioético acerca da eutanásia. Cadernos de Saúde Pública, 21(1), 111-119. https://doi.org/10.1590/S0102$-311 \times 2005000100013$

Spineli, V. M. C. D., Kurashima, A. Y., \& De Gutiérrez, M. G. R. (2015). The process of palliative sedation as viewed by physicians and nurses working in palliative care in Brazil. Palliative \& Supportive Care, 13(5), 1293-1299. https://doi.org/10.1017/S1478951514001278 